\title{
DIREITO INTERGERACIONAL E TRANSVERSALIDADE: O CADERNO DE CIDADANIA E VOZES INFANTIS
}

\author{
Ana Claudia Delfini Capistrano de Oliveira ${ }^{1}$ \\ ORCID: 0000-0002-7154-9020 \\ Caroline Vieira RuscheL ${ }^{2}$ \\ ORCID: 0000-0002-6916-4156
}

Resumo: O projeto de extensão "Direito Intergeracional e Transversalidade", da Univali atua nas comunidades escolares com crianças em risco social em Itajaí. O objetivo do projeto é dar visibilidade às vozes infantis sobre questões sociais a partir de ações educativas. Neste artigo, apresentamos os resultados de uma pesquisa desenvolvida sobre participação, família e gênero nas oficinas realizadas em 2017. O referencial teórico apoia-se na Sociologia da

Graduação em História pela Universidade Federal de Santa Catarina, mestrado e doutorado em Sociologia pela Universidade Federal de Santa Catarina. Professora titular da Universidade do Vale de Itajaí, em Itajaí, no curso de Pedagogia, no Programa de Mestrado Profissional em Gestão de Políticas Públicas/PMGPP e no mestrado/doutorado em Educação/PPGE. Tem experiência na área de Sociologia da Infância, Juventude e Políticas Públicas de Gênero. Coordenou os projetos de extensão Programa de Formação em Cidadania Infanto-juvenil e Observatório de políticas públicas entre 2004 e 2016. Participa dos Grupos de Pesquisa/CNPQ Dinâmicas Institucionais das Políticas Públicas do PMGPP e Educação e Trabalho do PPGE. Integrante da Rede Internacional RED HILA: Red Iberoamericana en Ciencias Sociales con enfoque de género com (Colômbia). Coordenadora do Grupo de Pesquisa/CNPQ: Sociologia da infância, relações de gênero e políticas públicas e representante da Universidade do Vale de Itajaí no Conselho Municipal dos Direitos da Mulher em Itajaí. E-mail: (anaclaudia.univali@gmail.com ).

2 Doutora em Direito pela Universidade Federal de Santa Catarina. Mestre em Direito pela Universidade Federal de Santa Catarina. Graduada em Ciências Jurídicas e Sociais pela Pontifícia Universidade Católica do Rio Grande do Sul. Professora da Universidade do Vale do Itajaí - UNIVALI. Foi professora substituta da Universidade Estadual de Santa Catarina - UDESC e da Pontifícia Universidade Católica do Rio Grande do Sul - PUCRS. Ministra as disciplinas de Direito Ambiental, com experiência profissional na Advocacia Ambiental em gestão e prevenção de conflitos. Pesquisadora de Direito Ambiental e Constelação Familiar aplicada ao Direito. Consteladora familiar. E-mail: (caroline.ruschel@univali.br). 
Infância. A metodologia consistiu na aplicação de um questionário individual com os alunos/as de diferentes faixas etárias durante as oficinas com o livro Caderno de Cidadania. Constatamos visões bem diferentes entre os meninos e as meninas, principalmente a respeito dos papéis familiares, entendidos de maneira diversa quando da análise sobre as relações de gênero, sendo necessário fomentar novos espaços de fala e protagonismo infantil nas escolas que acentuem reflexões intergeracionais e transversais.

Palavras-chave: Crianças. Sociologia da infância. Pontos de vista.

\title{
INTERGERATIONAL LAW AND TRANSVERSALITY: THE CITIZENS' BOOK AND CHILDREN'S VOICES
}

\begin{abstract}
The Univali's extension project "Intergenerational Law and Transversality" works in the school communities with children at social risk in Itajaí. The Project aims to give visibility to children's voices about social issues through educational actions. In this article, we present the results of a research developed on participation, family and gender in the workshops held in 2017. The theoretical reference is based on the Sociology of Childhood. The methodology consisted in the application of an individual questionnaire with the students of different age groups during the workshops with Citizens' book. We found very different views between boys and girls, especially regarding family roles, understood differently when analyzing gender relations, and it is necessary to foster new spaces for children's speech and protagonism in schools that emphasize intergenerational and transversal reflections.
\end{abstract}

Keywords: Children. Sociology of childhood. viewpoints.

\section{DERECHO INTERGERACIONAL Y TRANSVERSALIDAD: EL CUADERNO DE CIUDADANÍA Y VOCES INFANTILES}

Resumen: El proyecto de extensión "Derecho Intergeneracional y Transversalidad", de la UNIVALI actúa en las comunidades escolares con niños en riesgo social en Itajaí. El objetivo del proyecto es dar visibilidad a las voces infantiles sobre cuestiones sociales a partir de acciones educativas. En este artículo, presentamos los resultados de una investigación desarrollada sobre participación, familia y género en los talleres realizados en 2017. El referencial teórico se apoya en la Sociología de la Infancia. La metodología consistió en la aplicación de un cuestionario individual con los alumnos / as de diferentes edades durante los talleres con el libro Cuaderno de Ciudadanía. Se constatan visiones muy diferentes entre los niños y las niñas, principalmente respecto a los papeles familiares, entendidos de manera diversa en el análisis sobre las relaciones de género, siendo necesario fomentar nuevos espacios de habla y protagonismo infantil en las escuelas que acentuen reflexiones intergeneracionales y transversales. Palabras claves: Niños. Sociología de la niñez. Puntos de vista.

Submetido em: 27/08/2019.

Aceito em: 15/09/2019. 


\section{INTRODUÇÃO}

Este texto tem por objetivo analisar o ponto de vista das crianças e jovens participantes do projeto de extensão "Direito Intergeracional e Transversalidade", da Universidade do Vale do Itajaí-SC, voltado ao público infanto-juvenil, com atuação na cidade de Itajaí e região. Este projeto integrava o Programa de Extensão UNICIDADE, um programa intercentro que reunia o Centro de Ciências Jurídicas, Sociais e Políticas e o Centro de Ciências Sociais Aplicadas da Universidade do Vale de Itajaí - Univali, cujo objetivo principal era aglutinar os projetos de extensão destes centros e implementar um Programa de Formação voltado ao público infanto-juvenil centrado nos Direitos Fundamentais, no Estatuto da Criança e do Adolescente e nos Direitos Socioambientais. Deste programa, resultou a estruturação de um material didático-pedagógico para ser utilizado nos âmbitos da educação formal e comunitária chamado Caderno de Cidadania, composto por três módulos: a) Cidadania e Direitos Fundamentais; b) Estatuto da Criança e do Adolescente e c) Cidadania Socioambiental.

Em 2006, o Caderno de Cidadania teve sua publicação com uma tiragem inicial de nove mil cópias, financiado com recursos da Assembleia Legislativa de Santa Catarina. Desde então, foram firmadas diversas parcerias com várias escolas municipais do Vale de Itajaí (e Florianópolis) além de ONGs, projetos sociais e entidades civis, com as quais foram efetuadas mais de 60 Oficinas Educativas pela equipe do projeto e doados cerca de 7.0000 exemplares.

O Caderno de Cidadania (CC) fundamenta-se nos princípios da Pedagogia da Autonomia, de Paulo Freire, e nos princípios da cidadania participativa que contempla a criança como agente atuante e transformador de práticas e conhecimentos atinentes a sua realidade social. O projeto executa ações educativas na área da cidadania infanto-juvenil com oficinas didáticas nas escolas coordenadas pelas professoras do projeto e executadas pelos bolsistas, em parceria e colaboração da equipe pedagógica das escolas a fim de envolver as duas equipes de modo interdisciplinar. $\mathrm{O}$ projeto atua com crianças e jovens, na faixa etária entre 08 e 18 anos, em situação de risco ou vulnerabilidade social, matriculados na rede pública de ensino, nas cidades de Itajaí e Grande Florianópolis.

Neste texto apresentamos um recorte dos resultados de oficinas realizadas com crianças e jovens que participaram da pesquisa qualitativa através de um questionário produzido pela equipe do projeto sobre seus pontos de vista a 
respeito da participação social feminina e masculina e dos papeis de gênero na família, durante o ano de 2017, na cidade de Itajaí.

O artigo parte do referencial teórico da Sociologia da Infância/SI ao estudar as relações sociais das crianças como atores sociais e seus pontos de vista sobre as normas de gênero. Em tempos de autoritarismo e conservadorismo político, como os projetos "Escola sem Partido" e os ataques à "ideologia de gênero", urge fomentar novos espaços de fala e protagonismo para as crianças e jovens nas escolas terem a chance de se posicionarem como cidadãs de seus próprios mundos. Com esta pesquisa, constatamos visões bem diferentes entre os meninos e as meninas, principalmente a respeito dos papeis familiares, entendidos de maneira diversa quando da análise sobre as relações de gênero, etnia e classe.

\section{SOCIOLOGIA DA INFÂNCIA}

A consolidação de um campo de estudos denominado Sociologia da Infância (SI) revoluciona o atual estado da arte das pesquisas sobre e com crianças. Novas posturas teóricas e metodológicas têm sido alçadas por vários sociólogos para pensar a infância no mundo contemporâneo, dentre eles James e Prout (1990, p. 115), quando mencionam:

A criança é uma construção social. Infância é compreendida como uma construção social. Desse modo, ela fornece um quadro interpretativo que permite contextualizar os primeiros anos da vida humana. A infância, vista como fenômeno diferente da imaturidade biológica, não é mais elemento natural ou universal dos grupos humanos, mas aparece como um componente específico tanto estrutural quanto cultural de um grande número de sociedades.

Tendo em conta que a infância é uma construção social, uma variável que não pode ser inteiramente separada de outras variáveis como classe social, a Sociologia da Infância estuda as relações sociais das crianças como atores sociais na construção de suas vidas sociais e das vidas daqueles que as rodeiam, portanto, os métodos etnográficos são particularmente úteis para o estudo da infância.

Delgado e Muller (2005) mostram-nos que as principais dificuldades nas pesquisas com crianças estão relacionadas à lógica adultocêntrica dos pesquisadores/as que se negam a reconhecer a validade dos pontos de vista e das culturas infantis. As culturas infantis constituem-se não apenas em mais uma fonte de pesquisa, mas principalmente em uma possibilidade de investigação acerca da infância. Pode-se entender que as crianças como atores sociais constroem suas 
próprias culturas relacionadas com sua geração e seu processo histórico de socialização. Durante muito tempo, as ciências humanas afirmaram que a socialização das crianças deveria ser conduzida pelos adultos e pelas instituições que inculcavam saberes e determinavam práticas sociais consideradas, por eles, adequadas para a vida em sociedade. Desde a modernidade, ciências como a Pedagogia e Sociologia desenvolveram teses a respeito da homogeneidade do processo de socialização infantil com vistas ao disciplinamento e introjeção de valores que pudessem moldar, na criança, o adulto em formação.

É certo que não se pode tratar o tema da socialização de uma forma homogênea, mas aqui a discussão refere-se apenas à crítica do caráter passivo e adultista que este tema apresenta na tradição sociológica, crítica que é reiterada por diversos autores, como Montandon que lembra que "de maneira geral, os trabalhos que estudam as relações entre gerações e destinam lugar importante às crianças, são amparados por uma abordagem unilateral da socialização (MONTANDON, 2001, p.38)

A contribuição da Sociologia da Infância reside, justamente, na revisão paradigmática do conceito de socialização e dos significados epistemológicos da própria noção de infância a partir de duas teses: 1) o reconhecimento da existência de uma cultura infantil e da aptidão cultural das crianças entendidas agora como atores sociais e 2) o entendimento da infância como construção social e não apenas uma condição biológica/etária.

Na opinião de Montandon (2001, p.36-39), as pesquisas que discutem o conceito de geração associados à infância e o estudo das crianças como atores sociais acabam por abordar quatro categorias temáticas específicas: 1) as relações entre gerações; 2) as relações entre crianças; 3 ) as crianças como um grupo de idade e 4) os diferentes dispositivos institucionais dirigidos às crianças. Tais categorias permitem análises pluridiversas que dialogam com o que Sarmento (2002) caracteriza como a "a crise social da infância", perceptível em pelo menos quatro espaços estruturais distintos: 1) o espaço da produção (trabalho), 2) o espaço doméstico (família e socialização), 3) o espaço da cidadania (escola e esfera política) e 4) o espaço comunitário (relações de pares e as culturas infanto-juvenis) (SARMENTO, 2002, p.268-269).

O esgotamento das ideias unívocas de criança, infância e socialização sinaliza para a crise do modelo prescritivo e normalizador das práticas e saberes escolares sobre as crianças, ou seja, há uma crise institucional que questiona os mitos legitimadores da modernidade: "o mito do individualismo, o mito da nação agregado de indivíduos, o mito do progresso nacional e individual, o mito da socialização e continuidade do ciclo de vida e o mito do Estado como guardião da 
Nação"(SARMENTO, 2002, p.269.) Para este autor, cabe à Sociologia da Infância estudar a crise social da infância a partir da crítica a estes mitos, além de propor uma nova epistemologia da infância à medida que:

Se propõe a interrogar a sociedade a partir de um ponto de vista que toma as crianças como objeto de investigação sociológica por direito próprio, fazendo acrescer o conhecimento, não apenas sobre infância, mas sobre o conjunto da sociedade globalmente considerada. A infância é concebida como uma categoria social do tipo geracional por meio da qual se revelam as possibilidades e os constrangimentos da estrutura social. [...] Há outras dimensões estruturais que se cruzam com a categoria social da infância e que colocam cada ser social numa topografia complexa de relações (SARMENTO, 2005, p. 364).

Nesta topografia complexa de relações está situado, em nossa análise, o espaço da cidadania escolar aqui entendido como um dos espaços mais importantes para a ressignificação do conceito de democracia e cidadania infantil e juvenil, além de ser um dos espaços vitais para o exercício da participação social e política.

Discutir cidadania implica em esboçar respostas que deem conta das amarras sociais que ainda emperram a participação de inúmeros grupos sociais ao acesso e vivência cotidiana da cidadania. Na grande maioria destes grupos sociais, estão crianças e jovens condenados à não-cidadania. A escola pública é considerada por diversos segmentos sociais como o "maior patrimônio popular de um país", mas diante do descaso com a educação a palavra "popular" ganha estigmas como "popular é sinônimo de pobreza" e por isso as escolas públicas não precisam primar pela qualidade de ensino, uma vez que seus alunos já estão em condição de "subalternidade".

Este estigma reduz o ensino a mero instrucionismo por meio do qual o conhecimento é "repassado", "transmitido" aos alunos, o que gera uma atitude passiva diante do conhecimento e um imobilismo diante da própria sociedade. Certamente que este estigma contribui para a desvalorização dos professores, tanto em termos de formação e remuneração como também contribui para desmotivá-los na superação de todo tipo de instrucionismo e autoritarismo em sala que impeça o exercício da participação do aluno na conquista de sua cidadania. Assim, desde o início do projeto, foi necessário pensar sobre a forma como hoje se apresenta a cidadania no contexto escolar, afinal, como observa CANDAU (1995, p. 14):

[...] a escola, que deveria exercer um papel de humanização a partir da aquisição de conhecimentos e de valores para a conquista do exercício pleno da cidadania, tem muitas vezes favorecido a manutenção do status quo e refletido as desigualdades da sociedade, reforçando as diferenças entre ricos e pobres. 
Ora, se a escola, em vez de humanizar e preparar para a cidadania reforça a desigualdade social e "desciviliza” o aluno, então é preciso começar do zero. Não adianta falar de participação, de conscientização (aliás, uma palavra bastante problemática) para uma criança ou um adolescente que não se sente assim, que não se vê nem como cidadão e nem como sujeito, nas palavras do sociólogo Demo: "Cidadania é a competência humana de fazer-se sujeito para fazer história própria e coletivamente organizada." (DEMO, 1995, p.01). Estas palavras apresentam os dois pilares que norteiam o Caderno de Cidadania - Em primeiro lugar, fazer-se sujeito para fazer história própria e em segundo lugar, fazer história própria, mas coletivamente organizada.

Se a escola é uma entidade representativa da sociedade civil, ela deve ser palco não só de discussão e diálogo, mas também de desenvolvimento de hábitos e atitudes transformadoras que podem, na sua persistência e continuidade, formar agentes transformadores de um bairro, de uma cidade, de uma nação e do mundo. É preciso refletir sobre estes conceitos a partir de algumas conquistas já consolidadas na sociedade, como a "democracia cidadâ" ou de uma "cidadania participativa", e neste caso, a participação das crianças/jovens pode ser o caminho para a difusão dos direitos sociais como extensão da cidadania infanto-juvenil.

Considerar a cidadania de crianças no Brasil com um mínimo de senso de realismo é lembrar as palavras de Mary del Priore: "num país onde, há quinhentos anos, a formação social da criança passa mais pela violência explicita ou implícita do que pelo livro, pelo aprendizado e pela educação, raramente aproximam as crianças de conceitos como civilidade e cidadania." (2000, p.105). Para mudar esta história, é preciso refletir sobre como a escola auxilia, ou dificulta, a democracia participativa das crianças, não apenas pela difusão ou reconhecimento de direitos, mas pela vivência cotidiana de uma prática democrática e inclusiva. Por isso, entendemos que toda a discussão sobre cidadania e democracia infantil fica incompleta se não trouxer em seu bojo as relações de gênero. As questões de gênero são discutidas nas oficinas durante a aplicação de um instrumento analítico que tem por objetivo compreender as percepções das crianças e jovens a respeito das identidades de gênero vivenciadas em suas famílias e em seus pontos de vista pessoais.

\section{METODOLOGIA E DESCRIÇÃO DE RESULTADOS DAS OFICINAS}

As metodologias que privilegiam os pontos de vista das crianças, as suas interações intergeracionais, experiências e culturas infantis, são muito valorizadas pelos teóricos da Sociologia da Infância. 
As atividades do projeto são realizadas mensalmente e consistiram em atividades educativas com base em metodologias de participação propostas pelo Caderno de Cidadania, material paradidático que contém 3 módulos: 1) Cidadania e direitos humanos; 2) Estatuto da criança e do adolescente e 3) cidadania socioambiental. Os questionários foram aplicados pelos bolsistas e pelos acadêmicos contemplados com a bolsa do Artigo 170 do Estado de Santa Catarina, em cumprimento ao serviço voluntário sob a monitoria dos bolsistas do Programa, sob a supervisão dos professores das escolas e da equipe do projeto.

A metodologia consistiu na aplicação individual de um questionário elaborado pela equipe, o questionário é dividido em duas partes, na primeira se pedem os dados para a composição social, esses relativos às questões geracionais de gênero e de raça/etnia. Na segunda parte, apresenta-se discussões qualitativas sobre participação social, família e gênero. O questionário foi respondido individualmente e por escrito pelos 35 participantes, dentre as quais 15 meninos, 15 meninas e 05 jovens do sexo feminino, com predominância da cor branca, seguida da morena, parda e negra, conforme se autodeclararam.

Observou-se maior inserção de crianças das idades de 10,11, 12, e de 14 a 18 (com maior adesão das crianças de 10 e 11 anos como respondentes das sérias de $4^{\circ}$ ao $7^{\circ}$ ano) e 05 jovens respondentes na idade dos 18 anos. Há uma fraca inclusão social no que tange às questões étnicas, sobretudo aos indígenas e aos negros. Certamente que a proporção demográfica permite entender esta baixa porcentagem, uma vez que o percentual para os negros nas cidades apontadas não ultrapassa os $12 \%$, mas este dado não deve desconsiderar a falta de cidadania racial e étnica no Brasil, pois, de acordo com Silva (2007, p.49):

\footnotetext{
O acesso das crianças negras às instituições de Educação Infantil por vezes ainda reproduz um modelo pautado na exclusão social que caracteriza o sistema educacional brasileiro, contrariando o reconhecimento dos direitos sociais já estabelecidos e do direito à educação de todas as crianças, assegurado pela. Constituição de 88, pelo 40ECA/90 e pela Nova LDB. Mesmo assim, o acesso das crianças de 0 a 6 anos à Educação Infantil não é garantido, pois a demanda é superior ao número de vagas oferecidas às crianças pelo poder público dos municípios.
}

$\mathrm{Na}$ segunda parte os temas versam sobre os direitos das crianças/jovens, a sua participação social, e as relações de gênero no âmbito familiar. Ao serem questionadas sobre o ECA - Estatuto da Criança e do Adolescente - observou-se que as crianças possuem pouco conhecimento sobre esta legislação, enquanto os jovens souberam se posicionar mais. Dentre os direitos mais importantes considerados 
pelas meninas está a família, em segundo lugar, elas elegeram a educação e a vida como essenciais às crianças. Por sua vez, os meninos elegeram a educação como sendo o direito mais importante para as crianças, seguido do direito da alimentação, conforme suas respostas: "Ir a aula", "Cuidar do corpo", "Ter alimentos".

Os meninos entendem seus deveres relacionando-os ao meio-ambiente, às entidades de acolhimento institucional (abrigo), alimentação e à vida e aos amigos, numa leitura mais social e pública do que a visão privada e familiar das meninas. Entre os jovens, prevaleceu o direito à educação e à participação social. Neste contexto, o Caderno de Cidadania permitiu uma interação entre crianças e jovens como mediador das discussões sobre direitos e deveres, contribuindo para um ambiente pedagógico de respeito e de participação democrática. Para os meninos, a questão dos direitos das crianças, educação e meio ambiente foram muito enfatizadas ao passo que as meninas enfatizaram a família e a educação em suas respostas.

É muito significativo perceber que, na fala das meninas, o direito à família aparece mais frequentemente do que na fala dos meninos e dos jovens, o que nos permite pensar a centralidade da família nas vivências pessoais e subjetivas destas meninas, e até mesmo uma valorização maior dos laços familiares atrelada à socialização infantil.

Nesta mesma linha de raciocínio, Javeau (2005, p. 385) afirma que "as crianças devem ser consideradas uma população ou um conjunto de populações de pleno direito (cientifico), com seus traços culturais, seus ritos, suas linguagens, suas imagens ações ou, suas estruturas de modelo de ações". Neste sentido, tanto meninas como meninos não viram qualquer dificuldade em afirmarem que as crianças devem participar da sociedade, o que foi corroborado também pelos jovens ali presentes. Curiosamente, neste bloco todos responderam à entrevista. Não houve qualquer abstenção.

Para mensurar o padrão de cidadania infanto-juvenil vivida pelo grupo, foi perguntado para as crianças e os jovens onde eles/elas participam cotidianamente, as meninas e os meninos citaram a escola, o bairro e a cidade, não houve nenhuma diferença de gênero significativa em relação à participação das crianças em eventos e atividades na cidade, como por exemplo, a limpeza de praias, rios, atividades da escola na Prefeitura e na associação de moradores do bairro, mas é possível perceber diferenças de gênero na fala dos meninos quando relacionam sua participação em atividades de cidadania mais relacionados aos espaços públicos, como Prefeitura e entidades beneficentes, enquanto as meninas limitaram-se a considerar a sua participação na escola, bairro, praias e entidades. As jovens responderam que a cidade é o local de maior participação na resolução de problemas sociais, elas assumiram mais facilmente sua participação nos espaços públicos do que as meninas menores. 
Sobre as representações sociais de gênero e família, foi perceptível a compreensão de uma composição familiar com algumas características particulares: muitas pessoas vivendo na mesma casa, famílias conjugais e monoparentais, grande número de filhos e uma clara compreensão dos papeis de gênero traduzida nos binômios homem-trabalho, mulher-casa.

De acordo com os pontos de vista das meninas e das jovens, as tarefas domésticas delas estão eminentemente classificadas dentro do ambiente privado do lar e com os atributos de cuidado e ajuda que repetem o padrão binário e naturalizador das tarefas socialmente entendidas como femininas: arrumar o quarto, lavar louça, estender a roupa, arrumar a casa. Já os meninos limitam-se a: encher o litrão de água, lavar o banheiro, passar o pano no chão e tirar o lixo. Em geral, os meninos descrevem menos variações de atividades, enquanto as meninas estão sempre responsáveis pela manutenção da limpeza no lar.

Percebe-se que as atividades dos meninos exigem força, virilidade, e das meninas atividades que não exigem força e se restringem ao ambiente do interior do lar. Não foi analisado o nível de frequência em que essas crianças realizam essas atividades, contudo, vemos que as meninas não estão só encarregadas em arrumar o quarto em que dormem, mas também realizam pelo menos 03 atividades a mais que os meninos, por ex: cuidar do irmão, ajudar os pais e tirar o lixo. Fica evidente que as tarefas que as meninas realizam é utilizado como um ensaio para vida adulta. A disparidade nas relações de gênero na infância, das crianças das escolas públicas do Vale do Itajaí, não é diferente da realidade nacional. A pesquisa 'Por ser menina no Brasil', realizada nas cinco regiões do Brasil em diversas escolas em vários municípios, elaborada pela PLAN, revela no contexto nacional, as grandes disparidades de gênero nas tarefas domesticas: 76,8\% das meninas lavam louça e $65,6 \%$ limpam a casa, enquanto apenas $12,5 \%$ dos seus irmãos homens lavam a louça e 11,4\% dos seus irmãos homens limpam a casa. Daniela Finco (2008, p.06) reflete sobre o grande desafio da sociedade e da escola que passa por acomodar e dar resposta à individualidade no seio da diversidade e da pluralidade:

A função social assumida pela escola, nas suas múltiplas relações escolares revela a naturalização das diferenças de gênero instituídas socialmente e historicamente entre meninos. Essa visão predominantemente do que é ser menino e menina está ancorada em estereótipos construídos ao longo do tempo. Todavia, a escola continua imprimindo, sob novas formas, sua marca distintiva, sobre os indivíduos, através de múltiplos e discretos mecanismos, como pequenos gestos cotidianos que chegam a nos passar despercebidos; em reações automáticas, cujos motivos nos escapam e que repetimos sem ter, muitas vezes que os interiorizamos no processo educacional, sobretudo, os espaços de educação 
infantil acabam reforçando habilidades distintas para meninas e meninos depositando nestas expectativas quanto ao tipo de desempenho intelectual e postura considerados pelas convenções sociais 'mais adequados' para cada sexo. Assim ambos os sexos recebem educação diferenciada, embora partilhando do mesmo espaço, lendo as mesmas literaturas, ouvindo as mesmas histórias e sendo acompanhados pela mesma professora. Nesse sentido, a diferença está na postura e no tipo de intervenção aparentemente imperceptível e "inocente" quando os educadores interagem com as crianças.

Solicitamos que relatassem as tarefas domésticas de seus pais, a grande maioria dos pais e mães trabalha fora e as tarefas oscilam entre o cuidado com a casa, a cargo das mulheres, e o mercado de trabalho. As tarefas refletem a naturalização do esquema binário mulheres-trabalhadoras e do lar e homens-provedores, responsáveis pelo pagamento das contas mais pesadas, em contar com a "ajuda financeira" das mães.

Ao responderem a pergunta: Em sua opinião, homens e mulheres têm os mesmos direitos e a mesma participação social?, Todas as crianças foram afirmativas, entretanto, prevaleceu um entendimento aparentemente mais inclusivo nas respostas a esta pergunta uma vez que compreenderam a igualdade de direitos e participação na esfera pública, tanto homens quanto mulheres "trabalham fora e cuidam da casa", mas que não é necessariamente uma igualdade vivenciada na esfera do lar. Desta forma, há uma afirmação de igualdade jurídica e política e uma naturalização da desigualdade privada no que diz respeito aos papeis no interior do lar.

Tal paradoxo foi amplamente discutido pelas meninas que opinaram veementemente, delas vieram frases bastante significativas e emblemáticas como: "mulher cuida da casa", "mulher acolhe todos", sinalizando as relações de gênero no sentido do cuidado e acolhimento como atributos femininos. Neste universo de respostas, uma menina esbraveja: "mulheres não são escravas de ninguém” como a querer apontar uma necessidade de superação de uma condição social imposta à mulher na qualidade de subalterna, submissa, quase uma escrava.... Obviamente que esta fala é forte, e ecoa uma representação naturalizadora de papeis domésticos na qual esta menina parece se situar.

O mesmo não pode ser dito sobre os meninos, nem todos quiseram participar, o que sinaliza que muitos não se sentem à vontade para tratar deste tema (inclusive por um padrão de socialização que os inibe a ter estes posicionamentos), "deixando" a discussão "para as meninas", mas os que responderam, reiteraram tanto o cuidado feminino quanto a divisão binária destes papeis. Ao que tudo indica, o homem como ajudador e a mulher como cuidadora são papeis que as crianças entendem como balizadoras destas relações, ou seja, ao dizer que "homem e mulher 
trabalham fora e cuidam da casa" não significa que este "cuidar da casa" retrate uma divisão igualitária e de gênero no âmbito doméstico.

Ao contrário, reforça ainda mais o estereótipo de que os homens contribuem para este papel através de sua ajuda e provisão financeira, enquanto que as mulheres "apenas" cuidam da casa, ainda que trabalhem fora. Meninas e meninos concordam que sua participação social deve ser garantida pelo acesso e exercício de seus direitos, contudo, parecem ter dificuldades em perceber as disparidades que existem nas relações de gênero no plano doméstico. Todo esse processo é visto como algo natural, passado de gerações, portanto, é visto como algo imutável, "sempre foi assim", haja visto que no próprio ambiente doméstico estas desigualdades também são naturalizadas.

Quando questionadas sobre a questão do matrimônio, todos/as disseram que querem se casar e 09 meninas justificaram: "para não ficar sozinhas". Isso nos revela que o desejo pelo casamento é socialmente mais reforçado pelas meninas que temem "ficar solteironas", ou ainda, que percebem mais diretamente as possíveis dificuldades vivenciadas em seus próprios lares monoparentais, cuja gestão da vida doméstica tende a ser mais custosa quando se é só.

\section{CONSIDERAÇÕES FINAIS}

Infâncias, crianças, jovens, juventude e políticas públicas são como fragmentos de uma malha social que, no Brasil, é quase sempre frouxa, pois faltam às crianças e aos jovens, políticas públicas, assim como falta às políticas públicas, a participação das crianças e dos jovens. As reflexões sociológicas, em especial a Sociologia da Infância e da Juventude, servem como linhas para ajustar essa malha, contribuindo para elaboração de políticas mais eficientes para estas parcelas da sociedade. A maneira como as crianças e jovens desenvolvem seus significados de mundo e de ação são atravessadas por relações de classe, gênero e etnia que não permitem uma classificação homogênea ou coerente destes mesmos significados. Sarmento (2002) afirma que as culturas da infância devem ser analisadas levando em consideração a produção cultural elaborada pelas próprias crianças nas interações entre seus pares, mas sem esquecer que esta produção também é fruto das interações delas com os adultos e de toda a produção industrial para a infância que compõem o que ele chama de administração simbólica da infância na qual "o mercado e a escola são integrantes centrais a par das políticas públicas para a infância" (SARMENTO, 2002, p.8). 
Neste sentido, as atividades do projeto aqui analisadas contribuem para a compreensão destas culturas infantis e juvenis a partir de seus relatos sobre as questões sociais que delineiam a forma como crianças e jovens entendem a sua cidadania. A partir das oficinas, percebe-se como o Caderno de Cidadania é entendido como mediador na efetivação dos direitos e deveres das crianças e jovens, para que se possa perceber as crianças e jovens como sujeitos de direitos e com suas próprias identidades de gênero. Sobre o direito de participação social, pode-se entender que as meninas se veem como participantes da sociedade nos mais diferentes segmentos, sendo que os meninos se encontram mais ligados ao ambiente público.

Sobre a família, foram poucos os questionamentos sobre os papeis masculinos e femininos no interior do lar, colaborando para uma visão tradicional e hierarquicamente masculina. Embora as crianças reconhecessem a participação feminina na sociedade e o mercado de trabalho, esta visão não é suficiente para alterar o padrão de família de acordo com as normas de gênero, o que leva a crer que há uma maior aceitação da cidadania feminina no espaço público desde que seja assegurada a divisão binária no espaço privado. Nesta questão, as jovens também se posicionaram semelhantemente às meninas, o que nos permite concluir que as diferenças geracionais não são suficientes para alterar as suas percepções acerca das relações de gênero e cidadania.

\section{REFERÊNCIAS}

CANDAU, V. M., SACAVINO, S. B., MARANDINO, M., MACIEL, A. G. Tecendo a cidadania: oficinas pedagógicas de direitos humanos. Petrópolis: Vozes, 1995.

DEMO, Pedro. Cidadania Tutelada e Cidadania Assistida. Campinas: Autores Associados, 1995.

DELGADO, Ana Cristina; MÜLLER, Fernanda. Abordagens etnográficas com crianças e suas culturas. In: Anais da 28 ${ }^{\mathbf{a}}$ Reunião Anual da ANPED, 2005.

FINCO, Daniela. Meninas e meninos na Educação Infantil: uma questão de gênero e poder. Disponível em: http://www.scielo.br/pdf/cpa/n33/10.pdf. Acesso em: 03 dez 2015. 
JAMES, A.; PROUT, A. Constructing and reconstructing childhood: Contemporany issues in the Sociological Study of Childhood. London: The Falmer Press, 1990.

JAVEU, C. Crianças: que objetivo dar a uma ciência social da infância? In: Educação \& Sociedade. Sociologia da Infância: Pesquisas com Crianças. Campinas, v.26, n.91, mai./ago. 2005. P. 379-389

MONTANDON, Cléopâtre. Sociologia da Infância: balanço dos trabalhos em língua inglesa. In: Cadernos de Pesquisa, n.112, pp.33-60, março./2001.

PLAN International Brasil. Por Ser menina no Brasil. Crescendo entre Direitos e Violências Pesquisa com meninas de 6 a 14 anos nas cinco regiões do Brasil. Disponível em: http://primeirainfancia.org.br/wp-content/uploads/2015/03/1por_ser_menina_resumoexecutivo2014.pdf. Acesso em: 09 dez 2016

PRIORE, M. História da criança no Brasil. SP: Contexto, 2004.

SARMENTO, M. J. Infância, exclusão social e educação como utopia realizável. In: Revista Educação e Sociedade, ano XXIII, n.78, abril/2002, pp.265-283.

SARMENTO, M. J. Gerações e alteridade: interrogações a partir da sociologia da infância. In: Educação e Sociedade. Dossiê: Sociologia da Infância- pesquisa com crianças. Revista CEDES, n.91, vol. 26, mai./ago. 2005, pp. 361-378.

SILVA, Cristiane Irinéia. Acesso das crianças negras à educação infantil: um estudo de caso em Florianópolis. Dissertação (Mestrado em Educação) Universidade Federal de Santa Catarina. Florianópolis, 2007. 